\title{
Ambulatory Assessment - Monitoring Behavior in Daily Life Settings
}

\section{A Behavioral-Scientific Challenge for Psychology}

\author{
Jochen Fahrenberg ${ }^{1}$, Michael Myrtek ${ }^{1}$, Kurt Pawlik², and Meinrad Perrez ${ }^{3}$ \\ ${ }^{1}$ Institute of Psychology, University of Freiburg, Germany, ${ }^{2}$ Department of Psychology, University of \\ Hamburg, Germany, ${ }^{3}$ Psychological Department, University of Fribourg, Switzerland
}

\begin{abstract}
Ambulatory assessment refers to the use of computer-assisted methodology for self-reports, behavior records, or physiological measurements, while the participant undergoes normal daily activities. Since the 1980 s, portable microcomputer systems and physiological recorders/analyzers have been developed for this purpose. In contrast to their use in medicine, these new methods have hardly entered the domain of psychology. Questionnaire methods are still preferred, in spite of the known deficiencies of retrospective self-reports. Assessment strategies include: continuous monitoring, monitoring with time- and event-sampling methods, in-field psychological testing, field experimentation, interactive assessment, symptom monitoring, and self-management. These approaches are innovative and address ecological validity, context specificity, and are suitable for practical applications. The advantages of this methodology, as well as issues of acceptance, compliance, and reactivity are discussed. Many technical developments and research contributions have come from the German-speaking countries and the Netherlands. Nonetheless, the current Decade of Behavior (APA) calls for a more widespread use of such techniques and developments in assessment. This position paper seeks to make the case for this approach by demonstrating the advantages - and in some domains - necessities of ambulatory monitoring methodology for a behavioral science orientation in psychology.
\end{abstract}

Keywords: ambulatory assessment (monitoring), computer-assisted methods, decade of behavior, ecological validity, electronic diary

Assessing human experience and behavior, both in the laboratory and in normal life settings, is a central task for psychology, whereby theoretical knowledge is validated in the field. Since the stimulating ideas of Kurt Lewin (1951), and gaining momentum in the 1970s and 1980s, psychologists have been drawing attention to comparisons between laboratory and field research, to issues of environmental psychology, ecological validity and practical relevance, not only in applied psychology, but also in basic research. Although attention to these issues has given rise to a wide range of sound and suitable field research methods, researchers' interest in these innovative empirical approaches does not seem to have grown to the same extent.

\section{Ambulatory Monitoring and Assessment}

Portable microcomputers first became available about 30 years ago. While the new technology soon found its application in medicine, it was used only rarely by psychol- ogists and psychophysiologists. Today, computer-assisted methods are even more elaborated and suitable for much broader usage (Fahrenberg, Leonhart, \& Foerster, 2002; Pawlik \& Buse, 1996). This provides interesting new opportunities for studying daily life activities in situ through:

- self-reports on activities, characteristics of situations/settings, well-being, subjective state, or clinical symptoms;

- psychometric testing under field conditions;

- observation and assessment of behavior;

- data on perceptions of self and others;

- monitoring environmental conditions that are relevant to behavior;

- continuous registration of cardiovascular and other physiological processes, outside of the laboratory or clinic;

- self-assessed medical parameters; or

- continuous recording of physical activity and motion patterns.

In medicine, this type of method is called ambulatory monitoring, and is described by the Medline Database as: "The use 
of electronic equipment to observe or record physiologic processes while the patient undergoes normal daily activities." It can be used to monitor at-risk patients and to control many clinical procedures in a patient's normal daily life.

For several decades, ambulant $24 \mathrm{~h}$ blood pressure monitoring and the use of electrocardiograms (ECG) to monitor cases of ventricular arrhythmia or ischemic episodes have become indispensable routine methods in medicine. Monitoring blood pressure has an immediate and convincing validity, since it records how blood pressure reacts to daily life conditions. This is essential for diagnosis and treatment, and hundreds of thousands of people may have been misdiagnosed and, consequently, mistreated before this equipment became available (see Hansen, Jeppesen, Rasmussen, Ibsen, \& Torp-Pedersen, 2006). This also serves as an instructive example of how fallible it may be to generalize solely on the basis of laboratory experiments and encourages us to ask if a lack of data from daily life may have led to systematic mistakes in other disciplines also, including psychology.

As this is a new area for psychology, the literature does not yet provide a single and uniformly defined term for referring to ambulatory assessment in psychology. So we use the term here in a broad sense, beyond specifically medical contexts, denoting the use of (mainly) electronic devices and computer-assisted methods of data collection suitable for use in the field to collect self-report data, behavior observation data, psychometric behavior measures, and physiological data in unrestrained daily life settings. Each year, close to 500 articles are published that deal with ambulatory monitoring in medicine and physiology. Of these, some 300 refer to blood pressure and electrocardiogram and another 40 to the analysis of motor behavior (Fahrenberg, 2006) - compared to as few as 20 or so (i.e., about $5 \%$ ) that are primarily focused on psychology.

Ambulatory psychological assessment has been used for research purposes in Germany since the early 1980s, when computer-assisted assessment emerged as a promising alternative to conventional stationary diagnosis (Pawlik \& Buse, 1982, 2002). In the following years, it gained profile also in the United States in the form of the experience sampling method (ESM: Csikszentmihalyi \& Larson, 1987; Hektner \& Csikszentmihalyi, 2002) for assessing changes in mood state in representative samples of situations. Until recently (Barrett \& Barrett, 2001), most ESM research in the United States was still employing a paper-pencil (booklet) format, while research in Europe since the 1980s has focused on the development of more advanced computer-assisted methods for infield research on personality or, for example, on stress and coping (Perrez \& Reicherts, 1989, 1996; Perrez, Schoebi, \& Wilhelm, 2000; Wilhelm, 2004; Wilhelm \& Perrez, 2001; Thiele, Laireiter \& Baumann, 2002), some of which was synchronized with physiological measures (see Fahrenberg \& Myrtek, 1996, 2001a,b, 2005) or conducted interactively (Myrtek, 2004; Myrtek, Brügner, Fichtler, König, Müller, Foerster, \& Höppner, 1988; Myrtek, Foerster, \& Brügner, 2001).

\section{The Predominance of Questionnaires}

These advances stand in contrast to the fact that, even today, questionnaires remain the predominant psychological instrument for collecting data on behavior in every-day life situations, be it in the form of standardized scales and inventories or of ad hoc constructed item lists and rating scales. While questionnaires are undoubtedly a suitable method for studying subjective (mental) representations of experience, attitudes, and behavior, such self-assessments cannot serve as a substitute for actual behavioral data collected in every-day life (Tourangeau \& Rasinski, 1988; see also Pawlik, 1988), and should not be interpreted as such. Nevertheless, psychologists continue to fall back on questionnaires where actual behavior records rather than their subjective representations are at stake; viz. in-field data on cognitive, social, or psychomotor behavior, on physical or psychological well-being, on moods and emotions, or on situational and setting characteristics or other external events.

In such questionnaire studies participants are often asked to give retrospective self-assessments that refer to periods of time that are not always precisely defined (like "the previous day" or "recently"). Also, countless studies have shown that such use of questionnaires is based on unjustified methodological optimism concerning the ability of an average person to make such assessments accurately (Todd, Tennen, Carney, \& Armeli, 2004), not to mention the inaccuracies that occur when participants are asked to make subjective inferences about their own or other people's behavior, or to estimate mean frequencies (Perrez, 2006). Convergent experimental data (i.e., studies on recall and hindsight biases; Pohl, 2004), autobiographical studies (Cohen, 1991; Cohen \& Java, 1995) and studies on daily life employing computer-assisted diaries (Smith, Leffingwell, \& Ptacek, 1999; Käppler, Brügner, \& Fahrenberg, 2001) have all demonstrated that gathering information retrospectively is a highly dubious methodology that records mental representations rather than the actual experience and behavior that one is looking for. For these reasons, it seems even stranger to find questionnaires used so frequently as an inadequate alternative to the direct ambulatory recording of experience and behavior.

\section{Nonequivalence of Questionnaire Data and Field Data from Ambulatory Assessment}

A study by Buse and Pawlik (1984) on person-situation interactions may serve as an early example. Following Mischel's (1969) criticism of personality research for overrating transsituational consistency of personality characteristics, questionnaire studies asking for (retro or prospective) self-assessment of one's behavior in different situations 
demonstrated large and significant person-situation interaction effects, giving rise to an interactional paradigm of personality research (Magnusson, 1980). Setting aside questions of the retro- or prospective accuracy of such assessments, the questionnaire design also lacks ecological validity when all persons are confronted with the same spectrum of settings; such an orthogonality of person and setting characteristics is not at all descriptive of actual life spaces (Pawlik \& Buse, 1992).

Rather than again assessing personality-situation interactions through questionnaires, Buse and Pawlik (1984) collected actual in-field data on their subjects' behavior and mood states in ambulatory assessments, following a balanced randomized time-sampling design that ensured that situations and settings would be picked up as they occurred in the course of a person's life (rather than quasi-orthogonalized as in questionnaire studies). To this end, they developed a small freely-programmable computerized behavioral-data recorder that would alert participants and ask them to report, inter alia, setting and situation characteristics, current behavior, mood state, and motives. Data collection was conducted over 2 nonconsecutive weeks, with an average of 10 recording periods per day. In addition, participants (138 students aged 15-17 years) were tested on a standard personality test battery. For this data conventional analyses of variances yielded far fewer significant personality-situation interaction terms than would be expected through chance. This leads to the conclusion that the substantial interaction terms found in questionnaire data are specific to this type of data, suggesting that mental representations of how one behaves in different situations follow the interaction paradigm, whereas ambulatory data follow a straight linear-additive model.

\section{Assessment Strategies}

Frequently raised objections to field research maintain that it would be next to impossible to conduct conclusive tests of hypotheses, to provide for accurate variations of conditions, or to control for interfering conditions through measures such as randomization. So the resulting multiple effects would fundamentally limit the internal validity of such studies. Although it may carry more weight, the fact that ambulatory assessment and field research are much more difficult and methodologically far more demanding than studies that merely rely on asking the participants about their behavior is hardly ever mentioned.

These methodological arguments and objections are partly obsolete, however, and deserve a much more differentiated discussion. While it is true that there are necessary limits in varying field settings as compared to varying experimental conditions (which makes the experiment the via regia of causal-analytical research), this should not obscure the fact that the artificial variation of conditions has its lim- itations with regard to their control and intensity. Further it is also possible to conduct intervention studies and control variations in the natural environment, in addition to the natural variations of conditions that daily life itself offers.

We use the term field experiments when research settings and/or treatments have not been arranged by the researcher (see Patry, 1982); for example, studying subjective well-being as a function of the presence or absence of a partner (under otherwise comparable conditions) or attributed reasons for being in a positive or negative mood (Buse \& Pawlik, 1996; Perrez \& Wilhelm, 2000).

Research designs and special assessment strategies have been developed for research on daily life, and changes in perspective between self-reports, measurements of behavior, and physiological measures have proved to be methodologically fruitful. Some recent approaches to structured and interactive monitoring have achieved an approximation to randomization and other laboratory principles of control, while dealing with only a relatively minor loss of ecological validity (Myrtek, 2004).

We can distinguish between the following sampling strategies and designs of psychological and psychophysiological monitoring and assessment (example methods given in the right column):

Continuous The continuous recording of a "data stream," Monitoring without further intervention, such as using ECG for monitoring at-risk patients, or recording body posture and motion patterns.

Time- or Event- The use of an attention test at different times of Dependent the day or under certain context conditions, reMonitoring cording context conditions relevant for certain behaviors, the automatic measurement of blood pressure in intervals of $20 \mathrm{~min}$, or monitoring symptoms such as panic attacks when they occur, and under certain conditions using timeand event-contingent designs.

Controlled The selection of certain natural settings, for ex(Structured) ample the work place or family, or arranged, Monitoring standardized conditions and certain tasks, in order to obtain inter- and intraindividual reference data.

Ambulatory The conduct of standardized psychological tests Psychometric with a portable behavior recorder under daily Testing life conditions following fixed time-, event- or combined time-event-sampling designs, recording data for one person under the following conditions: The research situation has not been arranged by the researcher, the observed behavior or experience is natural (i.e., not following instructions), the behavior or experience is registered immediately (i.e., with only a minimal temporal distance to the real event), and there is a referential system that permits individual diagnostic hypotheses (Wilhelm \& Perrez, 2001).

Field Experi- Randomized allocation of participants to condiment tions (interventions, pharmacological substances, etc.) or to standardized variations of settings under daily life conditions. 
Interactive Mon- Real-time analysis of ambulatory recordings itoring (physiological or psychological parameters, such as heart rate, ST reduction in the ECG, or previously recorded ratings of well-being or complaints) are used to prompt subjects to use a hand-held recording device for a self-report on the momentary setting and subjective state, whereby randomly triggered reports may serve as controls.

Symptom-Moni- For instance, monitoring the course of chronic toring and Self- diseases or behavioral problems (dependent on Management time of the day, certain situations or events), training of psychophysiological responses (e.g., relaxation) in daily life, or bidirectional communications with therapists, e.g., in cases of detecting prodromes of migraine.

The progress of psychological and psychophysiological ambulatory assessment has been documented in two volumes (Fahrenberg \& Myrtek, 1996, 2001a) with broadly international contributions, and this method can now be employed to assess a wide range of physiological and psychological parameters (see Ebner-Priemer, 2006; Wilhelm \& Perrez. 2004; and the review by Fahrenberg, 2006).

While there are undoubtedly many issues that must be primarily or exclusively studied in the laboratory, there are others, such as strain and stress at the work place or in the family context, which can only be examined adequately under naturalistic conditions. Does it not seem plausible that behavioral problems should also be analyzed in the contexts wherein they arise and are triggered: i.e., in real life?

Ambulatory monitoring has progressed most rapidly in areas where the practical benefit is most evident, such as the ambulatory registration of blood pressure, ECG, and the reliable recording of body posture and motion patterns (Bussmann, 1998; Foerster \& Fahrenberg, 2000). In the USA a similar expansion is currently taking place in the use of electronic diaries and other forms of "patient-reported outcome" within medical and health-psychological research (Hektner \& Csikszentmihalyi, 2002; Stone, Shiffman, Atienza, \& Nebeling, 2007).

\section{Example: Physical Complaints over the Course of the Day}

In order to analyze both gender and generation differences and the dependency on the time of day of physical complaints, Michel (in press) studied 173 families (totaling 568 participants) on 7 consecutive days with the computer-assisted family self-monitoring system FASEM-C (Perrez et al., 2000). Six times a day, pocket computers recorded the participants' somatic complaints and additional information, following a signal-contingent recording-design. Multilevel analyses revealed that somatic complaints occurred most frequently in mornings and evenings. Women had a similar course pattern to men throughout the day but registered more somatic complaints than men, whereas teenagers registered a different course pattern compared to adults: In the evening, complaints were more frequent and began earlier, but they reported fewer complaints on weekend evenings.

\section{Methodology}

Several advantages of computer-assisted assessment over conventional paper-pencil methods are obvious:

- Alert functions can follow a fixed scheme, a random time-sampling or event-sampling strategy, or can be adapted to individual daily patterns.

- Exact recording can be made of responses, reaction times, data recording times, and other data.

- Ambulatory psychometric testing offers the additional options of using chronometric tests, including items incorporating time-dynamics (in the easiest case: moving) and of adaptive tests.

- Flexible layout can be made for question and answer categories, visual analog scales, text input, audio channel with appropriate controls of plausibility.

- Nesting questions with tailored, sequential, and hierarchical strategies, with previous responses to questions accessible only at the researcher's discretion, as for control and correction is possible.

- There is an option to combine strategies, for example time- and event-dependent data collection.

- Reliable analysis can be made of missing data and of instances of noncompliance.

- Ease of data checking and transfer onto a stationary computer can be made for further statistical analysis, minimizing data transfer errors.

- Option for individualized assessment through computerized learning strategies is available.

- Interactive data collection, and real-time analysis of the sequential data are possible.

- Range of data collection with respect to number of variables and of periods of recording is practically unlimited.

- Concurrent and context-related data can be provided instead of retrospective and somehow aggregated memories.

In addition, recent developments in data transfer and audiovisual communication can be used:

- Uni- or bidirectional communication with the researcher or therapist over mobile phone;

- Possibility for web-based data transfer, audiovisual interaction and on-line data analysis, in some cases with feedback to the participant/client.

- Acceptance: Most researchers found a generally high ac- 
ceptance of the use of computer-assisted methods (e.g., Perrez et al., 2000). However, researchers very often select participants, or are working with patients, who instantly recognize the benefits of the method. For instance, many hypertension patients accept the system; as one such patient said, "Everyone is their own blood pressure researcher." Clients can also see the logic in using pain diaries to determine optimal medication and early warning symptoms of the approaching prodromes of migraine. This could lead to the impression that the average participant's acceptance for this method is much higher than psychology's willingness to use these innovative methods in research and practice.

- Reactivity: Methodological reactivity is not a specific property of ambulatory monitoring, but characterizes many psychological or physiological research methods. Being called-upon ("beeped") by an electronic diary several times during the day may initially appear to be an attractive experience, but might become a nuisance after a while, especially in certain situations. The data collection program can allow for the participant to delay, defer, or even deny data input in such circumstances. ECG electrodes or a sensor system to detect motion patterns are very unobtrusive, and can be forgotten most of the time. Postmonitoring interviews reveal which details are perceived as a hassle, and should, therefore, be modified.

- Compliance: Common experience shows that it is never the case that all participants or patients in a study will do as they are told all the time. Many do not fill in their questionnaires, diaries, well-being, or complaint lists when they are supposed to, but after the event, often completing several at once. Methodological studies using electronic controls have also shown that compliance in taking medicine, measuring blood sugar, checking the level of cortisol in saliva in the morning, and so on, varies considerably. Computer-assisted monitoring can achieve a much higher compliance, coupled with high data accuracy, and in any case the ambulatory assessment methodology also guarantees full records with respect to compliance criteria.

- Ethical aspects: Ambulatory assessment might evoke the impression that it intrudes more than other research methods into people's privacy, and obviously, as with other methods, one has to follow the principles of informed consent and data protection. In daily life, more than in the laboratory or under test conditions, participants can find themselves in unforeseeable situations that they would prefer not to have registered, in which case such data has to be deleted.

- Costs: The acquisition of a hand-held computer (PDA) is by no means costly any more. Part of the software is open source, or is available for a small license fee (small in comparison to the effort involved in developing it). Systems that register physiological functions, and which are able to preprocess the data or that meet the demands of ambulatory psychometrics (test diagnosis), are com- parable to the costs of acquiring high specification office PC equipment. Even the higher cost of the most advanced recorders/analyzers (two- to four times more expensive) are still significantly lower than those of setting up a suitable laboratory or electroencephalogram machine.

\section{Technical and Methodological State of the Art}

In both the German-speaking countries and the Netherlands, there has been a series of remarkable developments in central areas of this method (see the European Network for Ambulatory Assessment at http://www.ambulatory-assessment.org/). This is true for both technical equipment and task-specific software, and includes

- The only behavior recorder that was specifically developed for the ambulatory application of psychological tests, while also being suitable for psychological self-reports and registering situational context conditions, following the data acquisition design of one's choice;

- The most advanced recorder/analyzer for physiological multichannel registration;

- The only computer-assisted method suitable for assessing stress and coping in the family;

- The only system (hardware/software combination) for systematic behavior observation in the field;

- A device for continuous, noninvasive measurement of finger blood pressure;

- The only recorder for multiple environmental parameters, such as background noise, light, environmental temperature, air pressure, relative humidity, etc.;

- Reliable algorithms for the automatic detection of motion patterns and disorders during the day through calibrated multiple accelerometry (24-h-motion protocol);

- Real-time algorithms for the detection of emotionally conditioned increases in heart rate, which interactively ask participants for self-reports on the current situation and well-being, either event-contingently or randomly;

- Years of experience in developing software and assessment strategies for self-reports about behavior, emotions, strains and coping strategies, social contacts and support, as well as daily-life family interactions and the development of user-friendly hand-held PC software allowing participants to construct matrices for the behavior of themselves and of those around them;

- Experience in multimodal methodology, i.e., with control procedures and parallel registration of subjective, behavioral, and physiological changes in daily life.

In the last decade, research teams in other European countries and in the USA have continued to develop ambulatory monitoring further, and it has been used in numerous projects. 


\section{Ecological Validity}

The term ecological validity might be frequently employed, but it has been used in a relatively vague way, unlike (for example) external validity, which can be operationalized directly as the correlation of criteria. Ecological validity is a multireferential concept, just like the concept of internal validity. It refers to the methodological evaluation of research design and data collection under daily life conditions, taking into account a series of aspects, difficulties, and possible control strategies. Essentially, it deals with the question of which settings and " $\mathrm{Ge}$ schehenstypen" (Lewin, 1951) of daily life are represented.

The experiment maintains its status as the gold standard of controlled observation and concise testing of hypotheses under the most stringent possible methodical isolation of the phenomena in question. However, from the perspective of specific context, the laboratory and the field are not fundamentally opposed alternatives, but offer complementary research approaches (Patry, 1982). Rather than allowing internal and ecological validity, the laboratory and the field, to stand against each other, it is essential to remove this opposition by developing new, combined research strategies, which are validated in the laboratory while at the same time being close to daily life conditions.

In the year 2000, following on the "Decade of the Brain," the onset of the "Decade of Behavior" was announced in the United States. More than 70 scientific organizations now want to draw public attention to behavioral sciences and promote willingness for funding. Essentially, this is calling for a practical behavioral and social science to improve health, security, and education (see also American Psychological Association, 1999). Here the innovative methodology of ambulatory assessment opens a new window and makes it possible to study individual experience and behavior under daily life conditions.

\section{Acknowledgments}

This paper is an abridged and translated version of an article originally published in German: Fahrenberg, J., Myrtek, M., Pawlik, K., \& Perrez, M. (2007). Ambulantes Assessment - Verhalten im Alltagskontext erfassen. Eine verhaltenswissenschaftliche Herausforderung an die Psychologie. Psychologische Rundschau, 58, 12-23. It is published here with permission of the publisher and the copyright holder, Hogrefe Verlag.

\section{References}

American Psychological Association. (1999). "Decade of Behavior" moves forward. APA MONITOR Online, 30(3). http:// www.decadeofbehavior.org/index.cfm

Barrett, L.F., \& Barrett, D.J. (2001). An introduction to computerized experience sampling in psychology. Social Science Computer Review, 19, 175-185.

Buse, L., \& Pawlik, K. (1984). Inter-Setting-Korrelationen und Setting-Persönlichkeit-Wechselwirkungen: Ergebnisse einer Felduntersuchung zur Konsistenz von Verhalten und Erleben [Between-setting correlations and setting-personality interactions: Results of a field-study of behavioural consistency.] Zeitschrift für Sozialpsychologie, 15, 44-59.

Buse, L., \& Pawlik, K. (1996). Ambulatory behavioral assessment and in-field psychological testing. In J. Fahrenberg \& M. Myrtek (Eds.), Ambulatory assessment: Computer-assisted psychological and psychophysiological methods in monitoring and field studies (pp. 29-50). Seattle, WA.: Hogrefe \& Huber.

Bussmann, H. (1998). Ambulatory monitoring of mobility-related activities in rehabilitation medicine. Delft, The Netherlands: Eburon.

Cohen, G. (1991). Memory in the real world. East Sussex: Erlbaum.

Cohen, G., \& Java, R. (1995). Memory for medical history. Accuracy of recall. Applied Cognitive Psychology, 9, 273-288.

Csikszentmihalyi, M., \& Larson, R. (1987). Validity and reliability of the experience-sampling method. The Journal of Nervous and Mental Disease, 175, 526-536.

Ebner-Priemer, U.W. (Ed.). (2006). Ambulantes psychophysiologisches Monitoring - neue Perspektiven und Anwendungen [Ambulatory assessment - New perspectives and applications]. Frankfurt a. M.: Peter Lang.

European Network for Ambulatory Assessment (2006). Homepage at http://www.ambulatory-assessment.org/.

Fahrenberg, J. (2006). Assessment in daily life ... 2000-2005. Retrieved August 6, 2007, from http://www.ambulatoryassessment.org/.

Fahrenberg, J., Leonhart, R., \& Foerster, F. (2002). Alltagsnahe Psychologie mit hand-held PC und physiologischem MessSystem [Psychology of daily life based on hand-held PC and physiological recording system]. Bern: Huber.

Fahrenberg, J., \& Myrtek, M. (Eds.). (1996). Ambulatory assessment: Computer-assisted psychological and psychophysiological methods in monitoring and field studies. Seattle, WA: Hogrefe and Huber Publishers.

Fahrenberg, J., \& Myrtek, M. (Eds.). (2001a). Progress in ambulatory assessment: Computer-assisted psychological and psychophysiological methods in monitoring and field studies. Seattle, WA: Hogrefe and Huber Publishers.

Fahrenberg, J., \& Myrtek, M. (2001b). Ambulantes Monitoring und Assessment [Ambulatory monitoring and assessment.] In F. Rösler (Ed.), Enzyklopädie der Psychologie. Serie Biologische Psychologie. Band 4: Grundlagen und Methoden der Psychophysiologie (pp. 657-798). Göttingen: Hogrefe.

Fahrenberg, J., \& Myrtek, M. (2005). Psychophysiologie in Labor, Klinik und Alltag. 40 Jahre Projektarbeit der Freiburger Forschungsgruppe Psychophysiologie - Kommentare und Neue Perspektiven [Psychophysiology in the laboratory, clinic, 
and field. 40 years of research - Commentaries and new perspectives]. Frankfurt a. M.: Lang.

Foerster, F., \& Fahrenberg, J. (2000). Motion pattern and posture: Correctly assessed by calibrated accelerometers. Behavior Research Methods, Instruments \& Computers, 32, 450-457.

Hansen, T.W., Jeppesen, J.R., Rasmussen, S., Ibsen, H., \& TorpPedersen, C. (2006). Ambulatory blood pressure monitoring and risk of cardiovascular disease: A population based study. American Journal of Hypertension, 19, 243-50.

Hektner, J.M., \& Csikszentmihalyi, M. (2002). The experience sampling method: Measuring the context and content of lives. In R.B. Bechtel \& A. Churchman (Eds.), Handbook of environmental psychology (pp. 233-243). New York: Wiley.

Hektner, J.M., Schmidt, J.A., \& Csikszentmihalyi, M. (2007). Experience sampling method. Measuring the quality of everyday life. Thousand Oaks, CA: Sage.

Käppler, C., Brügner, G., \& Fahrenberg, J. (2001). Pocketcomputer-unterstütztes Assessment mit MONITOR: Befindlichkeit im Alltag, Methodenakzeptanz und die Replikation des Retrospektionseffektes [Pocket-computer assisted assessment of subjective state, compliance, and replication of the negative retrospection effect]. Zeitschrift für Differentielle und Diagnostische Psychologie, 22, 249-266.

Lewin, K. (1951). Field theory in social science. New York: Harper and Brothers.

Magnusson, D. (1980). Personality in an interactional paradigm of research. Zeitschrift für Differentielle und Diagnostische Psychologie, 1, 17-34.

Michel, G. (in press). Daily patterns of symptom reporting in families with adolescent children. British Journal of Health Psychology.

Mischel, W. (1969). Continuity and change in personality. American Psychologist, 24, 1012-1018.

Myrtek, M. (2004). Heart and emotion. Ambulatory monitoring studies in everyday life. Cambridge, MA: Hogrefe \& Huber.

Myrtek, M., Brügner, G., Fichtler, A., König, K., Müller, W., Foerster et al. (1988). Detection of emotionally induced ECG changes and their behavioral correlates: A new method for ambulatory monitoring. European Heart Journal, 9(Supplement N), 55-60.

Myrtek, M., Foerster, F., \& Brügner, G. (2001). Freiburger Monitoring System (FMS). Ein Daten-Aufnahme- und Auswertungssystem für Untersuchungen im Alltag: Emotionale Beanspruchung, Körperlage, Bewegung, EKG, subjektives Befinden, Verhalten [Freiburg Monitoring System (FMS). A data-acquisition system for research in daily life: Emotional strain, body position, activity, ECG, and subjective state]. Frankfurt: Peter Lang.

Patry, J.-L. (Hrsg.). (1982). Feldforschung [Field research]. Bern: Hans Huber.

Pawlik, K. (1988). "Naturalistische” Daten für Psychodiagnostik: Zur Methodik psychodiagnostischer Felderhebungen ["Naturalistic" data for psychological assessment: The methodology of in-field assessments]. Zeitschrift für Differentielle und Diagnostische Psychologie, 9, 169-181.

Pawlik, K., \& Buse, L. (1982). Rechnergestützte Verhaltensregistrierung im Feld: Beschreibung und erste psychometrische Überprüfung einer neuen Erhebungsmethode [Computer-assisted behaviour recording in the field: Description and first psychometric evaluation of a new method of study]. Zeitschrift für Differentielle und Diagnostische Psychologie, 3, 101-118.
Pawlik, K., \& Buse, L. (1992). Felduntersuchungen zur transsituativen Konsistenz individueller Unterschiede im Erleben und Verhalten [In-field studies of transsituation consistency of individual differences in experience and behavior]. In K. Pawlik \& K.H. Stapf (Eds.), Umwelt und Verhalten [Environment and behavior] (pp. 25-69). Bern: Huber.

Pawlik, K., \& Buse, L. (1996). Verhaltensbeobachtung in Labor und Feld [Behavior observation in the laboratory and in the field]. In K. Pawlik (Eds.), Enzyklopädie der Psychologie. Differentielle Psychologie und Persönlichkeitsforschung. Band 1. Grundlagen und Methoden der Differentiellen Psychologie [Encyclopedia of psychology: Differential psychology and personality research. Vol. 1: Foundations and methods of differential psychology] (pp. 359-394). Göttingen: Hogrefe.

Pawlik, K., \& Buse, L. (2002). AMBU. Ambulatory monitoring and behavior-test unit. Göttingen: Hogrefe.

Perrez, M. (2006). Plädoyer für eine theorieadäquatere Methodik in gewissen Domänen der Psychologie [Arguments against the mismatch of theoretical assumptions and measures in certain domains of psychology]. Verhaltenstherapie \& Psychosoziale Praxis, 38, 319-330.

Perrez, M., \& Reicherts, M. (1989). Belastungsverarbeitung: Computerunterstützte Selbstbeobachtung im Feld [Coping with stress: Computer-aided self-observation under natural conditions]. Zeitschrift für Differentielle und Diagnostische Psychologie, 10, 129-139.

Perrez, M., \& Reicherts, M. (1996). A computer-assisted selfmonitoring procedure for assessing stress-related behavior under real life conditions. In J. Fahrenberg \& M. Myrtek (Eds.), Ambulatory assessment. Computer-assisted psychological and psychophysiological methods in monitoring and field studies (pp. 51-71). Seattle, WA: Hogrefe \& Huber.

Perrez, M., Schoebi, D., \& Wilhelm, P. (2000). How to assess social regulation of stress and emotions in daily family life? A computer-assisted family self-monitoring system (FASEM-C). Clinical Psychology and Psychotherapy, 7, 326-339.

Perrez, M., \& Wilhelm, P. (2000). Control psychology under the control of questionnaires. The search for an alternative assessment procedure. In W.J. Perrig \& A. Grob (Eds.), Control of human behaviour, mental processes, and consciousness (pp. 245-261). Mahwah, NJ: Erlbaum.

Pohl, R.F. (Ed.) (2004). Cognitive illusions. A handbook on fallacies and biases in thinking, judgment, and memory. New York: Psychology Press.

Smith, R.E., Leffingwell, T.R., \& Ptacek, J.T. (1999). Can people remember how they coped? Factors associated with discordance between same-day and retrospective reports. Journal of Personality and Social Psychology, 76, 1050-1061.

Stone, A., Shiffman, S., Atienza, A., \& Nebeling, L. (2007). The science of real-time data capture: Self-reports in health research. New York: Oxford University Press.

Thiele, C., Laireiter, A.-R., \& Baumann, U. (2002). Diaries in clinical psychology and psychotherapy: A selective review. Clinical Psychology and Psychotherapy, 9, 1-37.

Todd, M., §Tennnen, H., Carney, M.A., \& Armeli, S. (2004). Do we know how we cope? Relating daily coping reports to global and time-limited retrospective assessments. Journal of Personality and Social Psychology, 86, 310-319.

Tourangeau, R., \& Rasinski, K.A. (1988). Cognitive processes underlying context effects in attitude measurement. Psychological Bulletin, 103, 299-314. 
Published in: European Journal of Psychological Assessment, 2007, 23, 4, 206-213

which should be cited to this work

Wilhelm, P. (2004). Empathie im Alltag von Paaren. Akkuratheit und Projektion bei der Einschätzung des Befindens des Partners [Empathy in daily life of couples. Accuracy and projection when judging the emotional state of the partner]. Bern: Huber.

Wilhelm, P., \& Perrez, M. (2001). Felddiagnostik [Diagnostic under field conditions.]. In R.-D. Stieglitz, U. Baumann, \& H.J. Freyberger, Psychodiagnostik in Klinischer Psychologie, Psychiatrie, Psychotherapie (pp. 169-182). Stuttgart: Thieme.

Wilhelm, P., \& Perrez, M. (2004). How is my partner feeling in different daily-life settings? Accuracy of spouses' judgments about their partner's feelings at work and at home. Social Indicators Research, 67, 183-246.
Jochen Fahrenberg

Institute of Psychology

University of Freiburg

Belfortstraße 20

D-79106 Freiburg

Germany

E-mail jochen.fahrenberg@psychologie.uni-freiburg.de 